\title{
An online explorative study towards parents' opinions about organ donation: from individual decisions to family discussions
}

\author{
Marion J. Siebelink, PhDa, Marcel J.I.J.Albers, MD, PhD, Petrie F. Roodbol, Prof and \\ Harry B.M. Van de Wiel, Profa
}

\begin{abstract}
Background: Parental decisions about organ donation by their child are influenced by many factors. One of these factors may be a previous discussion under non-crisis circumstances. The question then arises whether parents have thought about this topic for themselves and discussed it with each other or with their child. Methods: An initial exploratory Internet survey to explore these discussions, parental opinions about school lessons on donation, the age threshold for a child to decide about donation, and determinants that influence these aspects. Questionnaire was sent to 14,000 panel members. We selected respondents with children younger than 16 years old.

Results: Questionnaire response rate was 35\%. Of all 1146 respondents with children, $84 \%$ had discussed the topic with their partner and, on average, $46.5 \%$ had discussed this with their child aged 10-16 years old. Religion and educational level of the parents were not related. Sixty-nine percent of parents were positive towards school lessons. Most of the children were allowed to decide for themselves at the age of $15 / 16$ years old.

Conclusion: Family discussions between spouses about donation do occur frequently; however, discussion with children can be improved. If desired, triggers for beginning these conversations could be provided through public information and schooleducation, which would also contribute to health literacy on this subject. Key words: child; education; family discussions; organ donation; parents.
\end{abstract}

http:/ / dx.doi.org/10.5546/aap.2014.eng.224

a. University Medical Center Groningen, University of Groningen, Groningen, the Netherlands.

b. St. Elisabeth Hospital, Tilburg, the Netherlands.

E-mail Address:

M.J. Siebelink:

m.j.siebelink@umcg.nl

Conflict of Interest:

None.

Received: 7-14-2013

Accepted: 1-16-2014 individuals thought about this topic for themselves and discussed it with each other and/or in a family setting? For adults, actual donation decisions are frequently influenced by whether or not the potential donor's wishes are known by the decision maker, typically a family member. ${ }^{4}$

In the case of a child, these family members are in most cases the parents. Even when the parents consider organ donation important, they often have not thought about the possibility of organ or tissue donation by their own child. Moreover, we know that children infrequently discuss donation at home. ${ }^{5}$ Whether parents discuss the topic with each other or with their child under non-crisis circumstances is also unknown. The importance of such family discussions, however, is stipulated both by the literature and by our experience that when parents are suddenly confronted with the question about donation, and they have discussed the topic with their child previously, they feel the urge to fulfil their child's wishes. ${ }^{3}$

In the Netherlands, organ donation by children younger than 16 years old does not take place without parental consent. The literature shows that previous family discussion is a strong predictor of consent to donate. ${ }^{3,4,6-8}$ Waldrop and colleagues have stated that family members should be encouraged to discuss their feelings about donation under non-crisis circumstances. ${ }^{3}$ Therefore, it is important to promote family discussions about organ donation. One way to promote such family discussions is through education in schools. $^{4}$

In general, from empirical evidence we know that from the age of 9 years 
children are cognitively and emotionally capable of providing assent under normal conditions. ${ }^{9}$ Moreover, research has shown that children from the age of 12 years on are capable of thinking and willing to think about organ donation. ${ }^{5}$ Nevertheless, as far as we know, studies on the awareness of parents about their child's opinion at ages younger than 12 are completely lacking. This raises the question of whether parents have thought about this topic, and discussed it with each other and with their child. We hypothesized that parents do not often discuss the topic within their families.

The present study was designed to explore whether parents and families had discussed organ donation with their child and what the factors were that had influenced whether these discussions took place. We also asked the respondents about their opinion concerning lessons on organ donation in schools and what they thought was the best age threshold for a child to decide about donation.

\section{MATERIALS AND METHODS}

Respondents were recruited from an online panel which is used by public television, commercial companies, and government. The aim of the panel is to gain insight into opinions about current and social topics. People are recruited for this panel through advertisements in newspapers and magazines.Although internet use is a valid methodology for exploratory studies this strategy has a certain risk of bias.

The questionnaire was sent out to 14,000 panel members by email in November 2007. All panel members were invited to respond, anonymous within four weeks.From the respondents, we selected all individuals with children aged 0 through 15 years. These age limits were chosen because, according to the Dutch Organ Donation Act, persons 16 years and older are authorized to make their own decision about organ donation. Under 16 years of age, parents are the legal representatives of the children.

The questions about donation were embedded in a larger survey which included 88 different current social items (e.g., politics, media consumption). For this study, we were able to select those items related to organ donation, including the question about a respondent's own registration in the Dutch Donor Register: positive (=consent), negative (=refusal), neutral (decision by next of kin or a specific person) or non-registered.

The questions about donation are given in Appendix 1. We extracted the age groups of the parents (see Table 1). We also extracted religion and type of education of the parent (see Table 2) from the dataset. The religions were divided

TABLE 1. Different age groups of the parents

\begin{tabular}{lc}
\hline Age group & \% \\
\hline $18-24$ & 0.8 \\
$25-34$ & 6.9 \\
$35-44$ & 57.3 \\
$45-54$ & 32.5 \\
$55-64$ & 2.3 \\
$65+$ & 0.2 \\
\hline
\end{tabular}

TABLE 2. Demographic variables of the respondents compared to the general population in the Netherlands

\begin{tabular}{|c|c|c|c|}
\hline \multirow[t]{2}{*}{ Demographic variables } & \multicolumn{2}{|c|}{$\begin{array}{l}\text { Respondents } \\
\quad n=1146 \\
830 \mathrm{M} / 316 \mathrm{~F}\end{array}$} & \multirow{2}{*}{$\begin{array}{c}\text { General population } \\
\% \\
\end{array}$} \\
\hline & $\mathbf{N}$ & $\%$ & \\
\hline \multicolumn{4}{|l|}{ Religion } \\
\hline Roman Catholic church & 255 & 22 & 29 \\
\hline Other religions (incl. Dutch Protestantism, Islam) & 358 & 31 & 29 \\
\hline Non-religious & 533 & 47 & 42 \\
\hline \multicolumn{4}{|l|}{ Education } \\
\hline High & 627 & 55 & 28 \\
\hline Middle/Low & 519 & 45 & 72 \\
\hline \multicolumn{4}{|l|}{ Donor registration } \\
\hline Non-registered & 517 & 45 & 59 \\
\hline Registered & 629 & 55 & 41 \\
\hline Positive (consent) & 504 & 44 & 20 \\
\hline Negative (refusal) & 65 & 6 & 11 \\
\hline Neutral (decision by next of kin or a specific person) & 60 & 5 & 10 \\
\hline
\end{tabular}


into Roman Catholic church, other religions (including Islam and Dutch Protestantism), and non-religious. Education of the parent was divided into high (university, high school) and middle/low education (primary and middle school). These demographic variables were chosen because they are well-known predictors of attitudes towards organ donation. ${ }^{5,10,11}$

Given the nature of the study a descriptive analysis was performed. The data were analysed with SPSS 17 (SPSS Inc., Chicago, IL, USA). Dependent variables were tested with a $\chi^{2}$-test. All statistical analyses were performed two-sided with $\alpha$ set at 0.05 .

\section{RESULTS}

A total of 4975 (35.5\%) respondents completed the questionnaire. Of these, we selected all 1146 individuals with children aged 0 through 15 years old. Of these, 1099 selected respondents were living with a partner. In total, 830 were male and 316 female. The selected respondents were taking care of 1591 children disaggregated by age; 478 parents had children age $0-5 \mathrm{y} / \mathrm{o}, 366$ had children 6-9 y/o, 258 had children 10-11 y/o, and 489 parents were caring for children aged 12-15 y/o.

Table 2 shows the demographic variables of religion, education, and donor registration of the 1146 respondents compared to the general population of the Netherlands. ${ }^{12,13}$

All respondents answered that they had heard about organ donation.

\section{Family discussion}

Of the 1099 respondents who were living with a partner, $925(84.2 \%)$ had discussed the topic of organ donation with their partner. Of these, 326 of the 1146 parents $(28.4 \%)$ had discussed the topic with their children (children's age distribution: aged $0-5$ years old $5.9 \%$, aged $6-9$ years old $23.1 \%$, aged $10-11$ years old $41 \%$; and aged $12-15$ years old 56\%). Combined for children aged 10-15 years, this figure was $46.5 \%$. Within the family mothers discussed the topic more often with their child than fathers (36,7\% vs $23,3 \%)$.

No relationship was observed between the educational level of the parents and whether they had discussed the topic with each other $(\chi 2$, $\mathrm{p}=0.426)$ or with their children $(\chi 2, p=0.499)$.

We found no relationship between religion and the prevalence of parental discussions $(\chi 2$, $\mathrm{p}=0.068)$ about organ donation, and between religion and discussions about donation between parents and their children $(\chi 2, p=0.793)$.

Parents who had registered themselves in the Dutch Donor Register had discussed this topic more often together $(\chi 2, p=0.018)$ and with their children $(\chi 2, p=0.014)$, as compared to those parents who were not registered. Moreover, parents with a positive registration had discussed it even more often with their children (35.3\% vs. $18.5 \%, \chi 2, p=0.01)$, as compared to parents with a neutral or negative registration.

Of the parents who had discussed the subject with their child, the most frequently mentioned reasons for this were "It's a normal task for a parent to make explicit the child's important wishes" and "It's an important topic"; sometimes parents mentioned that "It's a current topic." A few times parents mentioned that "It was a topic at school" and that "My child started this conversation triggered by (social) media."

When parents did not want to discuss this subject, the most frequently mentioned reasons were: "I think my child is still too young" and "I never considered discussing this with my child." Sometimes parents mentioned: "I don't want to think about this." A few times: "I don't want to become a donor" or "I don't have time to discuss this."

\section{School lessons}

Of the 1146 parents, 796 (69.4\%) parents favoured school lessons on this topic, 166 parents $(14.5 \%)$ were neutral, and 184 parents $(16.1 \%)$ were negative towards school lessons.

Figure 1 shows the age threshold for lessons. Of the 962 parents who were positive or neutral, $60.7 \%$ think the best moment to start these lessons is in primary school (i.e., before or at the age of 10-12 years old).

We found no relationship between the parents' opinion about school lessons and their educational level $(\chi 2, p=0.697)$. In addition, religion was not related to the parents' opinion about school lessons $(\chi 2, p=0.108)$.

Parents' own registration in the Dutch Donor Register was significantly related to the opinion on school lessons $(\chi 2, \mathrm{p}<0.001)$. Parents who are registered as positive more often think that school lessons on organ donation are a good tool for educating the child, as compared with parents who are registered as negative $(85.1 \%$ vs. $46.2 \%, \chi 2, p<0.001)$. Moreover, parents with a neutral registration more often think positively 
about education, as compared to parents who are registered as negative ( $73.3 \%$ vs. $46.2 \%)$.

The prevalence of parental discussion on this topic was not related to the ideas of parents towards school lessons. However, parents who had discussed this topic with their child were significantly more positive towards school lessons $(\chi 2, \mathrm{p}<0.001)$.

\section{Best age threshold to decide}

We asked the respondents at what age their child should first be allowed to decide about becoming a donor by himself (see Table 3).

Religion was related to what parents thought was the best age to decide; parents with a nonreligious or Roman Catholic background thought that their child should be allowed to decide at younger ages than parents of other religions $(\chi 2$, $\mathrm{p}<0.01$ ).

Also the educational level of the parents was related to what parents thought was the best age to decide to become a donor. Parents with a higher educational level more often thought that their child was able to make a decision at younger ages than parents with a lower educational level $(\chi 2, p=0.04)$.

In addition, the registration of the parents themselves in the Dutch Donor Register was related. Of the parents who were registered, $50 \%$ thought that their child should be able to decide before the age of $15 \mathrm{y} / \mathrm{o}$; of the parents who were not registered this figure was $20 \%(\chi 2, p<0.01)$.

\section{DISCUSSION}

In this study, we have explored the opinions of parents in the Netherlands about organ donation by their own children and the extent of their family discussions about this topic. To our knowledge, this is the first study on parental and parent-child discussions about organ donation in families.

This study shows that in the Netherlands most parents $(84 \%)$ have discussed this topic with their partner. On average, $46.5 \%$ of the parents have discussed this topic with their child aged 10 through 15 years old. In general, mothers discussed the topic more often than fathers. Of all parents, the majority (56\%) began this conversation starting at the age of 12 . This last figure corresponds with the findings reported by children in a previous study on children's opinions about organ donation. That study, with a comparable study design, had shown that $43 \%$ of the children aged 12 through 15 years reported

TABLE 3. Best age threshold to decide about becoming a donor

\begin{tabular}{ccc}
\hline age & $\mathbf{N}$ & \% \\
\hline $9 / 10$ & 84 & 7.3 \\
$11 / 12$ & 112 & 9.8 \\
$13 / 14$ & 149 & 13.0 \\
$15 / 16$ & 801 & 69.9 \\
\hline
\end{tabular}

FIGURE 1. Percentage and number of respondents (vertical axis) versus best age threshold for a lesson about organ donation in school (horizontal axis)

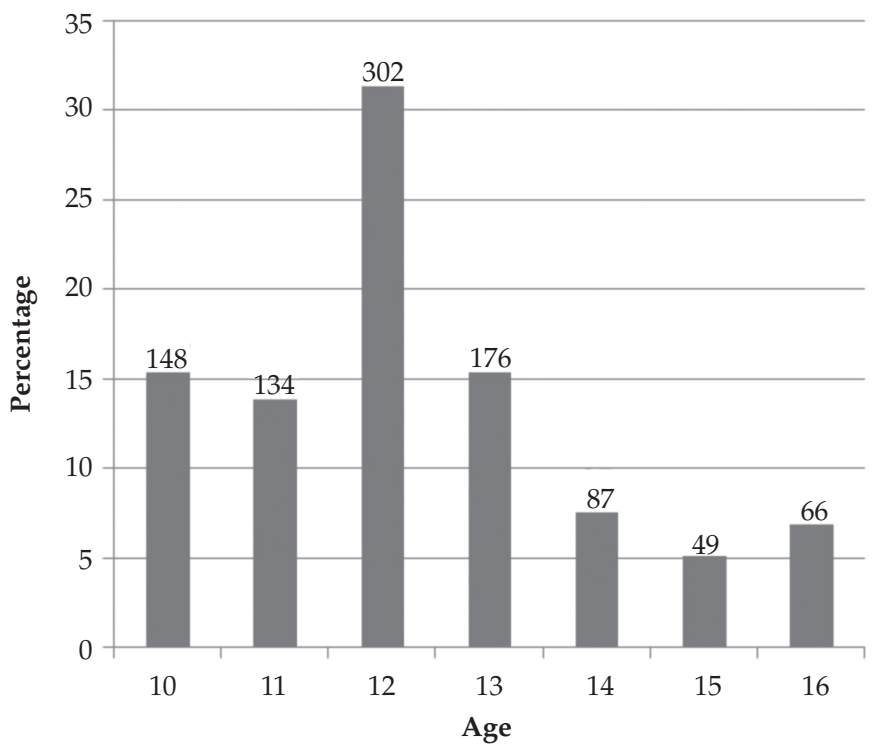


that they had discussed the topic at home more than once. ${ }^{5}$ In our present study, the extent of family discussions was found not to be related to the educational level or religion of the parents. Moreover, we do not find it surprising that parents who were registered in the Dutch Donor Register themselves more often discussed the subject in their families. This is in keeping with the findings of Morgan and Miller for adults; of those who had signed their donor card, most had discussed their wishes with family members. ${ }^{14}$

In our present study, parents also gave different reasons for not starting a discussion on this topic. One reason given was that they had never thought about the possibility of donation by their child. This is not remarkable because Dutch public information campaigns on organ donation only focus on adult donation; parents are not aware of the fact that organ donation is also possible for children. It is conceivable that parental awareness about organ donation increases with the age of the child. A second reason mentioned by parents for avoiding family discussion was that they didn't want to think about such a difficult topic.

Parents who did start a discussion with their child felt that this was a parental task. Media attention (e.g., a topic on a children's news program, public campaigns) often was found to be the trigger to start this conversation. When children themselves started this conversation, this was also sometimes triggered by social media. In the Netherlands, almost all children are active in social media, and these media increasingly confront children with various social topics. ${ }^{15}$ Another reason mentioned by the parents is that children start the conversation at home because of a lesson at school. We think that these communication channels, such as social media and school lessons, can be used to bridge the gap concerning information for parents and children on the subject.

Most parents supported the idea of school lessons about organ donation. Parents registered as positive on the Donor Register were the most supportive. Cantarovich and colleagues argued that, after school education on organ donation, children expected that their families would develop an interest in organ donation. ${ }^{16}$ Siminoff and colleagues point out that education is the best mechanism for informing the public and preparing families for an organ donation request. ${ }^{4}$ In addition, Randhawa pointed out that school programs could encourage active discussions about organ donation by treating it as a subject which aids children's social development. ${ }^{17}$

We also asked the parents what they thought was the best age for a child to decide about becoming a donor. Although most parents (70\%) thought that children aged 15-16 years old were at the best age to decide for themselves, $30 \%$ of the parents thought that their child was capable of deciding at a younger age. We found a relationship between the religion of the parents and the age that the child should be able to decide for himself about organ donation. Nonreligious or Roman Catholic parents thought that their child was capable of deciding at a younger age than parents of other religions. However, there are no other studies to compare these findings to. It is interesting to note that we found a relationship between educational level of the parents and the best age to decide; parents with a high educational level thought their children were capable of deciding at a younger age. In contrast, these parents did not discuss the topic more often with their child. More research is needed to put these results into perspective.

Some limitations should be pointed out. The present study was designed to explore whether parents and families discussed organ donation and to explore the factors that influenced this discussion. Since we were the first to do this, we chose to do a descriptive study and were unaware of the effects / group differences that could be expected, such as gender differences. Although we had a large sample, results with regard to self-administered questionnaires and group differences should be interpreted with some care due to a possible lack of power. Although the data were collected in 2007, we think our findings are still valid. Child organ donation is rarely discussed in the Netherlands and therefore the current situation will not have differed very much from the study period. Although we had an over representation of male respondents we speculate that our data is still generalizable. Some bias can be expected since the educational level of the respondents is slightly higher than the norm for the Dutch population. Moreover, although the questions related to donation were embedded in a larger questionnaire and the percentage of registration in the Dutch Donor Register was similar to the Dutch population, there was some bias; the percentage of respondents registered as positive was higher, when compared to the Dutch population as a whole.

Despite these limitations, we want to 
emphasize that we undertook this study to identify the extent of parental and family discussions about organ donation by the children. We know that family discussions are a key factor in proper decision-making about organ donation. From this study, we know that there is room for improvement in terms of discussion within the family. Media and social media attention and school education can be used as a trigger. There is parental support to develop these educational programs for children and their parents. Moreover, public campaigns should also be aimed at adults in their role as parents and should focus as well on family discussions in order to provide children and their parents with adequate opportunities to receive appropriate information.

\section{CONCLUSION}

\section{Key points}

- Most parents never discussed donation with their child.

- Parents support school lessons about donation.

- Most parents think that 15 years is the best age to decide about becoming a donor.

- For health policy: family discussions between parents and children about donation should be promoted.

\section{Acknowledgements}

We thank No Ties for their participation in the data assessment and their willingness to share their data for research purposes. We also thank Rosanne van der Krol (Master's student in psychology) and Dr. Karin Vermeulen (HTA researcher) for their contributions.

\section{REFERENCES}

1. Bellali T, Papadatou D. Parental grief following the brain death of a child: does consent or refusal to organ donation affect their grief? Death Stud 2006;30(10):883-917 .

2. Siebelink MJ, Albers MJ, Roodbol PF, van de Wiel HB. Key factors in paediatric organ and tissue donation: an overview of literature in a chronological working model. Transpl Int 2012;25(3):265-71.
3. Waldrop DP, Tamburlin JA, Thompson SJ, Simon M. Life and death decisions: using school-based health education to facilitate family discussion about organ and tissue donation. Death Stud 2004;28(7):643-57.

4. Siminoff LA, Gordon N, Hewlett J, Arnold RM. Factors influencing families' consent for donation of solid organs for transplantation. JAMA 2001;286(1):71-7.

5. Siebelink MJ, Geerts EA, Albers MJ, Roodbol PF, van de Wiel HB. Children's opinions about organ donation: a first step to assent? Eur J Public Health 2012;22(4):529-33.

6. Walker JA, McGrath PJ, MacDonald NE, Wells G, et al. Parental attitudes toward pediatric organ donation: a survey. CMAJ 1990;142(12):1383-7.

7. Rodrigue JR, Cornell DL, Howard RJ. Pediatric organ donation: What factors most influence parents' donation decisions? Pediatr Crit Care Med 2008;9(2):180-5.

8. Oliver RC, Sturtevant JP, Scheetz JP, Fallat ME. Beneficial effects of a hospital bereavement intervention program after traumatic childhood death. JTrauma 2001;50(3):440-6.

9. Ondrusek N, Abramovitch R, Pencharz P, Koren G. Empirical examination of the ability of children to consent to clinical research. J Med Ethics 1998;24(3):158-65.

10. Reubsaet A, BrugJ, van den Borne B, van Hoof H. Predictors of organ donation registration among Dutch adolescents. Transplantation 2001;72(1):51-6.

11. Smits M, van den Borne B, Dijker AJ, Ryckman R. Increasing Dutch adolescents' willingness to register their organ donation preference: the effectiveness of an education programme delivered by kidney transplantation patients. Eur J Public Health 2006;16(1):106-10.

12. Siebelink MJ. (Personal communication). Dutch Donor Register; figures on registration 2007. 2009-2012.

13. Centraal Bureau voor de Statistiek, Statistics Netherlands. Statline. 2007. Available at: http://www.cbs.nl/en-GB/ menu/themas/vrije-tijd-cultuur/publicaties/artikelen/ archief/2008/2008-2476-wm.htm y http://www.cbs.nl/ en-GB/menu/themas/onderwijs/publicaties/artikelen/ archief/2013/2013-3905-wm.htm [Accessed on: February 21, 2014].

14. Morgan SE, Miller JK. Beyond the organ donor card: the effect of knowledge, attitudes, and values on willingness to communicate about organ donation to family members. Health Commun 2002;14(1):121-34.

15. van Rooij AJ, Schoenmakers TM. Factsheet social media en gamen. Available at: http:/ / www.ivo.nl/UserFiles/File/ Publicaties / 2013-01\%20Factsheet\%20Social\%20media\%20 en\%20gamen.pdf. [Accessed on: February 22, 2013].

16. Cantarovich F, Fagundes E, Biolcalti D, Bacqué MC. School education, a basis for positive attitudes toward organ donation. Transplant Proc 2000;32(1):55-6.

17. Randhawa G. Targeting the UK's young potential donors: placing organ donation on the school agenda. Transplantationsmedizin 1998;10:38-40. 


\section{Appendix 1}

The questionnaire contained the following questions (translated from the original questionnaire):

1. Have you ever heard about organ and/or tissue donation?

$\mathrm{y} / \mathrm{n}$

2. Did you ever discuss the topic of organ donation with your partner?

$\mathrm{y} / \mathrm{n}$

3. What was your reason for discussing this with your partner?

Open

4. Why have you never discussed this topic with your partner?

Open

5. Did you ever discuss the topic of organ donation with your child?

$\mathrm{y} / \mathrm{n}$

6. What was your reason for discussing this with your child?

Open

7. What was your child's age when you discussed this topic?

Age groups

8. Why have you never discussed the topic with your child(ren)?

Open

9. What is your opinion about lessons on organ donation at school?

5 points scale

10. What is the best age to start these lessons?

Age groups

11. At what age should your child decide by him or herself about donation?

Age groups 